\title{
A radiation hybrid map of river buffalo (Bubalus bubalis) chromosome 7 and comparative mapping to the cattle and human genomes
}

\author{
T. Goldammer ${ }^{\mathrm{a}} \quad$ R. Weikard ${ }^{\mathrm{a}} \quad$ M.N. Miziara ${ }^{\mathrm{b}} \quad$ R.M. Brunner ${ }^{\mathrm{a}} \quad$ R. Agarwala ${ }^{\mathrm{c}}$ \\ A.A.Schäffer ${ }^{c}$ J.E. Womack ${ }^{d}$ M.E.J. Amaral ${ }^{b, d}$
}

${ }^{a}$ Forschungsbereich Molekularbiologie, Forschungsinstitut für die Biologie landwirtschaftlicher Nutztiere (FBN), Dummerstorf (Germany); ${ }^{\mathrm{b}}$ Departamento de Biologia, Instituto de Biociências, Letras e Ciências Exatas, IBILCE, UNESP, São José do Rio Preto, SP (Brasil); ${ }^{c}$ National Center for Biotechnology Information, National Institutes of

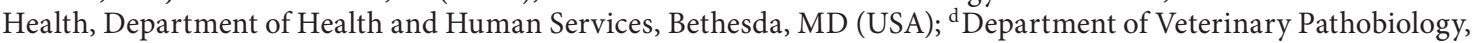
Texas A\&M University, College Station, TX (USA)

Accepted in revised form for publication by J. Smith, 26 October 2007.

\begin{abstract}
A preliminary radiation hybrid (RH) map containing 50 loci on chromosome 7 of the domestic river buffalo Bubalus bubalis (BBU; $2 \mathrm{n}=50$ ) was constructed based on a comparative mapping approach. The RH map of BBU7 includes thirty-seven gene markers and thirteen microsatellites. All loci have been previously assigned to Bos taurus (BTA) chromosome BTA6, which is known for its association with several economically important milk production traits in cattle. The map consists of two linkage groups spanning a total length of $627.9 \mathrm{CR}_{5,000}$. Comparative analysis of the BBU7 $\mathrm{RH}_{5,000}$ map with BTA6 in cattle gave new evidence for strong similarity between the two chromo-
\end{abstract}

somes over their entire length and exposed minor differences in locus order. Comparison of the BBU7 $\mathrm{RH}_{5,000}$ map with the Homo sapiens (HSA) genome revealed similarity with a large chromosome segment of HSA4. Comparative analysis of loci in both species revealed more variability than previously known in gene order and several chromosome rearrangements including centromere relocation. The data obtained in our study define the evolutionarily conserved segment on BBU7 and HSA4 to be between 3.5 megabases $(\mathrm{Mb})$ and $115.8 \mathrm{Mb}$ in the HSA4 (genome build 36) DNA sequence.

Copyright $\odot 2008$ S. Karger AG, Base
The economic importance of river buffalo as livestock species in many countries around the world is undisputed. More than 168 million domesticated river buffaloes (Bubalus bubalis (Linnaeus 1758) were counted worldwide, which is more than $11 \%$ of the Bovinae world livestock population

Grant GO-896/6-2 from the Deutsche Forschungsgemeinschaft and the Intramural Research Program of the National Institutes of Health, NLM supported this comparative mapping study in ruminants.

Request reprints from Tom Goldammer Forschungsbereich Molekularbiologie

Forschungsinstitut für die Biologie landwirtschaftlicher Nutztiere (FBN) Wilhelm-Stahl-Allee 2, D-18196 Dummerstorf (Germany) telephone: +49 38208 68708; fax: +4938208 68702

e-mail: tomgoldammer@fbn-dummerstorf.de
(Iannuzzi et al., 2003; FAO 2005, 2006, 2007). Construction of a high-resolution river buffalo gene map, linked with trait associated genome regions, will therefore be an important milestone for developing efficient breeding strategies and modern productive phenotypes. The map will be used as a tool for genome-wide analysis of functional diversity of trait associated candidate genes within the numerous described river buffalo breeds (e.g. FAO 2005, Kumar et al., 2007). Likewise, an elucidated genome of the river buffalo will contribute enormously to a better understanding of genome evolution in Ruminantia, specifically in domestic Bovidae. Various projects, including the definition of a river buffalo karyotype nomenclature (e.g. Iannuzzi, 1994; Popescu et al., 1996), and numerous synteny, fluorescence in situ hybridization (FISH), and Zoo-FISH mapping experiments (e.g. Iannuzzi et al., 1996, 1998, 2001, 2003; de Hondt et al., 1997; 
El Nahas et al., 2001; Di Meo et al., 2002) initiated the genome analysis in river buffalo and opened the gate for complex genome-wide studies such as RH mapping. A 5,000 rad whole genome radiation hybrid panel for river buffalo $\left(\mathrm{BBURH}_{5,000}\right)$ was recently generated by this mapping approach. The potential of this panel for genotyping RH markers by PCR and subsequent RH linkage map construction has been already confirmed (Amaral et al., 2007; Miziara et al., 2007; Stafuzza et al., 2007).

This study focused on comparative analysis of BBU7 by interspecies-specific transfer of cattle and human genome data to the river buffalo genome. Previous physical mapping has comparatively anchored five bovine genes and two microsatellite markers on BBU7, which made it possible to estimate the size and determine the orientation and order of conserved chromosome fragments between BBU7, BTA6, and the human reference chromosome HSA4 (Di Meo et al., 2000; Iannuzzi et al., 2001, 2003). A higher map resolution is required for a more detailed chromosome description that will allow trait association studies, and subsequently, the identification of positional candidate genes for functional studies. BBU7 received early attention in our buffalo mapping project because the homologous chromosome BTA6 harbors several quantitative trait loci for economically important traits, including milk production traits in dairy cattle as well as growth and body composition traits in meat cattle (e.g. Khatkar et al., 2004, 2005; Schnabel et al., 2005; Weikard et al., 2005; Polineni et al., 2006).

This study develops a first-generation RH map of the second largest acrocentric chromosome in river buffalo, BBU7, identifies chromosome rearrangements, analyses the comparative loci order, and determines evolutionarily conserved segments between BBU7, BTA6, and HSA4.

\section{Material and methods}

DNA sequences, primer design, genotyping by PCR,

DNA sequencing

Initially, genotyping experiments were performed with published primer sequences. Seventy-five DNA sequences (genes and microsatellite markers) for mapping were chosen from the BTA6 $\mathrm{RH}_{12,000}$ map (Rexroad III et al., 2000; Weikard et al., 2006). When available bovine primer sequences did not generate any PCR product with river buffalo genomic DNA or displayed weak typing signals after PCR amplification within the RH panel, markers were completely excluded from further genotyping or new primer pairs were designed based on bovine and human reference DNA sequences by genome database search at the National Center for Biotechnology Information (www.ncbi.nlm.nih. gov). The software program PRIMER3 (http://frodo.wi.mit.edu/cgibin/primer3/primer3_www.cgi) was used to design oligonucleotide primers for PCR (Rozen and Skaletsky, 2000). Genotyping by PCR of DNA sequences was performed in DNA from 90 selected RH cell lines of the BBURH $\mathrm{Br}_{5,000}$ panel (Amaral et al., 2007). The scoring of genotyping signals indicates presence (1) or absence (0) of RH markers within cell lines. Double typing of all DNA sequences within the BBURH $\mathrm{BH}_{5,000}$ panel increased the accuracy of retention data calculation for RH mapping; when the two typings gave discordant results, this was recorded as a 2 in the digitized input for map computation. PCR used in primer tests and hybrid cell lines followed a standard protocol (Goldammer et al., 2004). Taq cycle sequencing of bovine PCR products with the automated sequencer 310C (Applied Biosystems) identified corresponding river buffalo DNA sequences. NCBI BLAST (Altschul et al., 1997) search with the river buffalo DNA sequences identified similarity with corresponding bovine and human genome data.

Construction of the $\mathrm{BBU} 7 \mathrm{RH}_{5,000}$ map

The software packages rh_tsp_map 3.0 (Agarwala et al., 2000; Schäffer et al., 2007) and CONCORDE (Applegate et al., 2006) were used for RH map construction, using the maximum likelihood (MLE) criterion. We followed the steps in the rh_tsp_map tutorial (ftp://ftp. ncbi.nlm.nih.gov/pub/agarwala/rhmapping/rh_tsp_map.tar.gz) through placement of markers with respect to framework maps, but we did not assign final $\mathrm{cR}$ positions to the placed markers. The same procedure was used for maps of BBU6 (Stafuzza et al., 2007) and BBU1 (Miziara et al., 2007), except that in this study, we increased the LOD score threshold for constructing linkage groups to 7.0 because the overall collection of markers has grown, so that higher inter-chromosomal LOD scores would be expected to occur by chance.

\section{Results}

A total of 75 bovine genes and microsatellites were included in the RH mapping study. Fifty-seven of the available or newly designed bovine primer sets produced PCR products with river buffalo genomic DNA and reliable genotyping results within the $\mathrm{BBURH}_{5,000}$ panel. DNA sequencing of PCR products confirmed sequence specificity of mapped RH markers. Seven markers were dropped because they could not be included in the framework maps and could not be reliably placed with respect to the framework maps. The RH maps include the remaining $50 \mathrm{RH}$ markers (37 genes and 13 microsatellites) (Fig. 1). The first step of map construction resulted in the generation of two RH linkage groups. The map of the first group consists of eight $\mathrm{RH}$ markers (6 genes and 2 microsatellites) and has a length of $69.31 \mathrm{cR}_{5,000}$. The map of the second linkage group contains the remaining $42 \mathrm{RH}$ markers ( 31 genes and 11 microsatellites). The calculated length for this group is $558.55 \mathrm{cR}_{5,000}$. The orientation of the large group was determined because several markers shown near the upper end have pairwise inter-group LOD score $>5.0$ with a marker in the small group, while markers near the lower end appear unlinked to the small group. The orientation of the small group was made consistent with BTA6 because inter-group scores do not strongly favor one possible orientation of the small group over the other. The cytogenetic anchor loci for MTTP and BM1329 at position BBU7q21 and CSN3 at BBU7q32 (Iannuzzi et al., 2003) enabled the chromosome orientation of the BBU7 $\mathrm{RH}_{5,000}$ map as presented in Fig. 1 .

The BBU7 $\mathrm{RH}_{5,000}$ map is based on a framework map composed of $31 \mathrm{RH}$ markers. Seventeen RH markers, which did not meet the statistical criteria for a frame marker were placed in the most likely framework interval on the map. The marker retention frequency averaged $27.8 \%$, varying from $18.9 \%$ for DMP1 to $51.1 \%$ for NUP54 (Fig. 2). Table 1 presents additional information about RH markers, genotyping by PCR, and RH mapping results.

Comparison of the calculated locus order for BBU7 with the $\mathrm{RH}_{12,000}$ reference map for cattle BTA6 (Weikard et al., 2006) and with the cattle genome sequence map for BTA6 
River buffalo

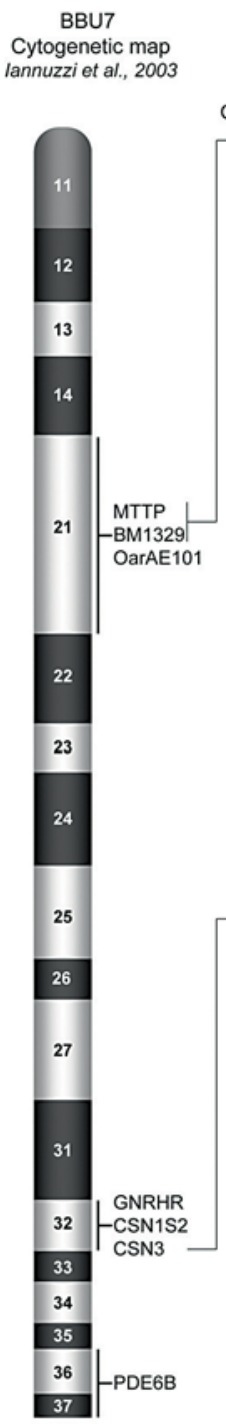

1

\section{Centromere}

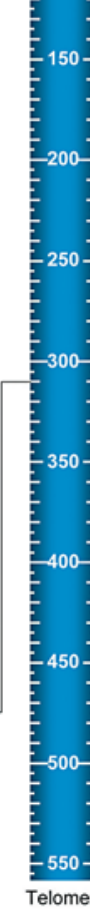

\section{BBU7}

RH map

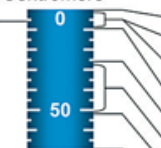

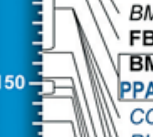


Table 1 (continued)

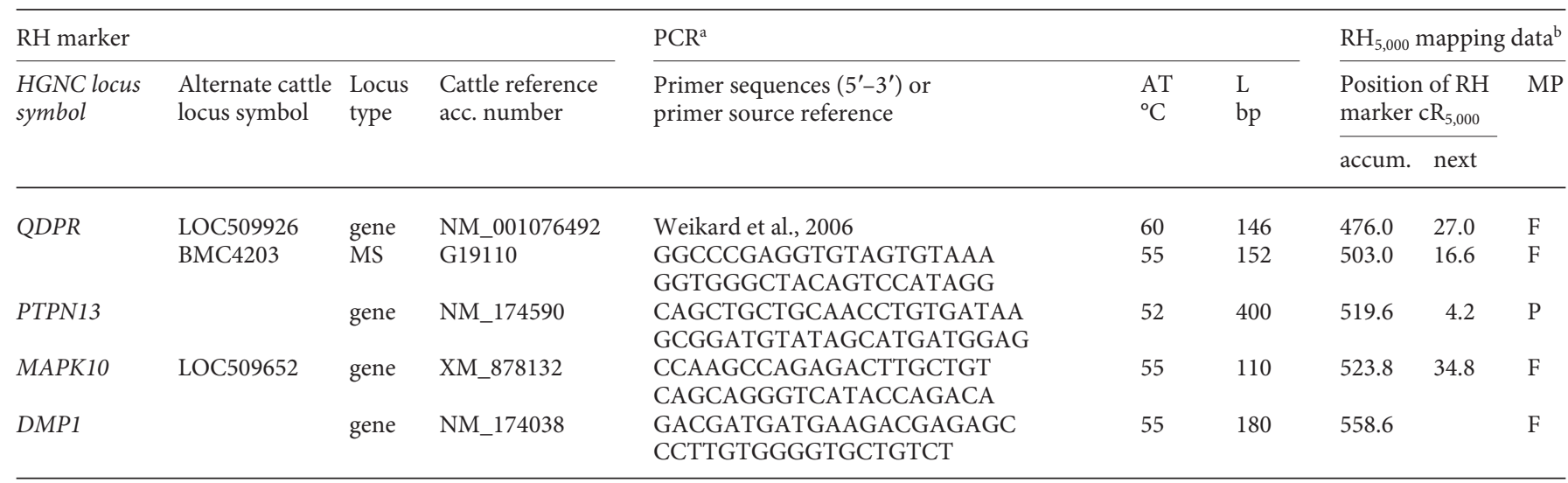

a AT: annealing temperature; L: length of PCR product.

b F: framework marker; Fi: marker with identical locus as framework marker; HGNC: HUGO Gene Nomenclature Committee; MP: marker placement; P: placed markers (CentiRay positions of placed markers were estimated by interpolation).

Fig. 3. Comparative map between gene loci in river buffalo BBU7 $\mathrm{RH}_{5,000}$ map and corresponding orthologous gene loci in human chromosome HSA4. Continuous blocks connected by lines identify related conserved syntenic chromosome segments between species. Breaks between blocks determine evolutionary breakpoints. A scale of the HSA4 DNA sequence (NCBI Homo sapiens build 36.2) and a cytogenetic drawing allow a detailed comparison of similarity between BBU7 and HSA4. A bold solid line represents a summary of single cytogenetic loci on HSA4 (precise loci order available at NCBI Homo sapiens build 36.2). Arrows indicate a suggested inversion in gene order of BBU7 segments compared with loci order of HSA4. Dotted lines identify genes of continuous segments of BBU7 separated on HSA4.

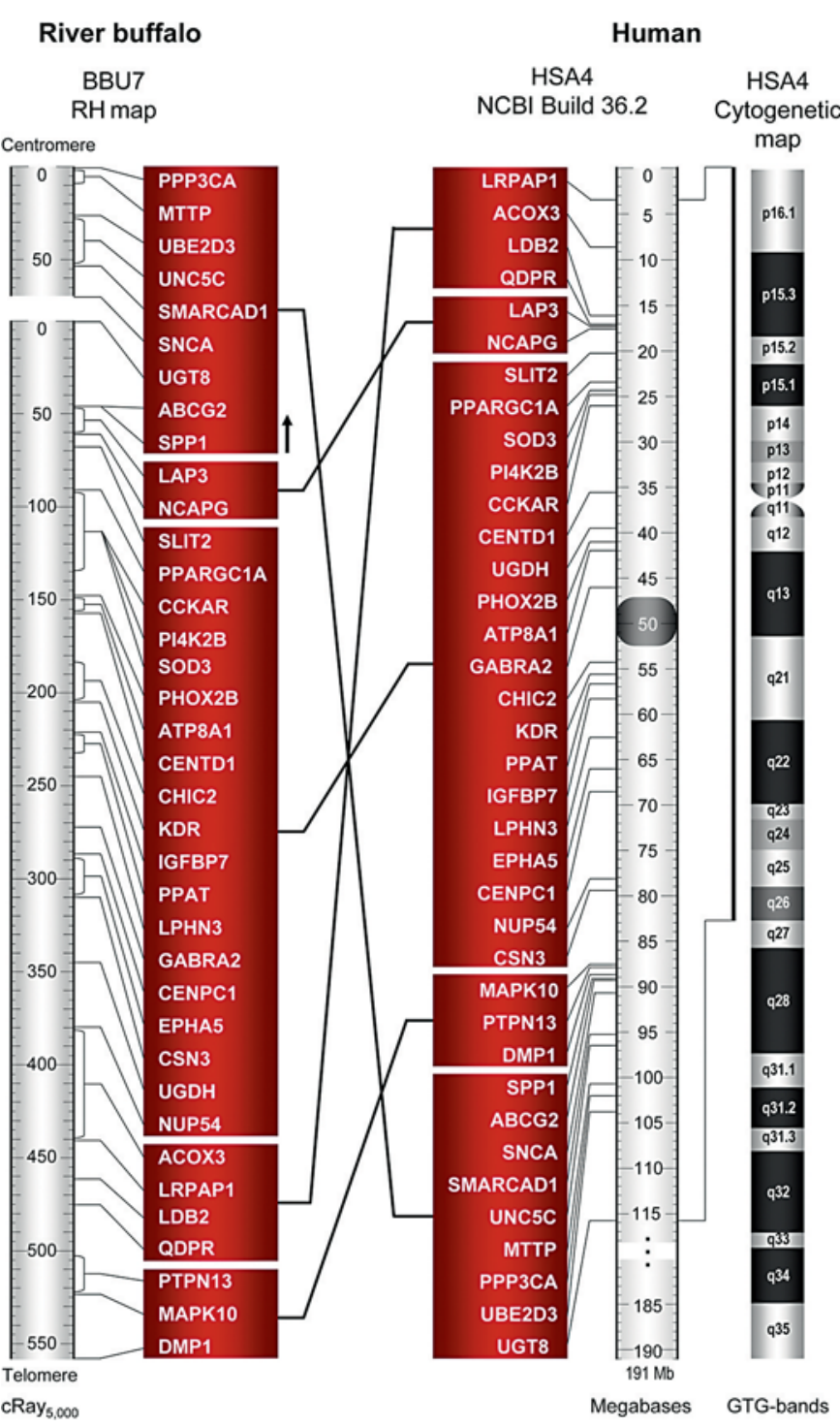




\section{Discussion}

We used a comparative mapping approach, based on available human and cattle genome data to construct an $\mathrm{RH}$ map for river buffalo chromosome BBU7. The $\mathrm{RH}_{5,000}$ map provides sufficient information for identification of syntenic blocks between related chromosomes of the three species and uncovers evolutionary breakpoint regions. Additionally, the map contributes new physical anchors, which enable improved in silico gene assignment to BBU7.

We mapped 50 of the 57 typed markers on river buffalo chromosome BBU7. Surprisingly, only 36 (48\%) of the initially tested 75 cattle primer sequences from the $\mathrm{RH}_{12,000}$ map of BTA6 (Weikard et al., 2006) amplified corresponding DNA sequences in river buffalo genomic DNA. Another twenty-one were developed by designing new sets of primers primarily in genome regions conserved between cattle and human. However, the drop out of numerous $\mathrm{RH}$ markers decreased density in some regions of the map. Thirty-seven gene loci allowed a comparative analysis with the human genome, and 13 nearly uniformly distributed microsatellite markers represent putative informative markers potentially useful in quantitative trait studies in river buffalo. Except for a few discrepancies and small rearrangements, we found that the BBU7 $\mathrm{RH}_{5,000}$ map has a similar marker order to BTA6. We found a locus for NUP54 on BBU7; NUP54 has been assigned by RH mapping on BTA6 (Weikard et al., 2006) and likewise on HSA4 (NCBI Homo sapiens build 36.2), but is not identified on the annotated Bos taurus genome build 3.1.

The most interesting loci in our map are UGT8 and NUP54. In cattle, UGT8 is located in a very proximal position of $6.1 \mathrm{Mb}$ on BTA6, which is about $13 \mathrm{Mb}$ away from $U B E 2 D 3$, the next distal locus with a comparative placement in the BBU7 $\mathrm{RH}_{5,000}$ map (NCBI Bos taurus build 3.1; Fig. 1). According to our data, UGT8 represents the distal boundary of conserved segments on HSA4 compared with BBU7. Although no corresponding position for UGT8 was identified in the BTA6 $\mathrm{RH}_{12,000}$ map (Weikard et al., 2006) and UGT8 shows only weak linkage with SNCA (RH linkage group 1) and is furthermore located in a relative high distance of $45.5 \mathrm{cR}_{5,000}$ to its next marker $A B C G 2$ in RH linkage group 2, we calculated its locus as proximal frame marker of RH linkage group 2 on BBU7. Mapping of more RH markers and some cytogenetic anchors in this chromosome region is required to define the exact position of UGT8 and to form a single linkage group with the remaining markers of the first linkage group. The high retention frequency of 51\% for NUP54, differs substantially from mean value of the other mapped RH markers and caused distances of $34.8 \mathrm{cR}_{5,000}$ and $61.6 \mathrm{cR}_{5,000}$ to its neighboring frame markers $U G D H$ and $L R P A P 1$, respectively. Perhaps the cattle primers for NUP54 amplified sequences of other genes in the NUP multigene family in some cell lines of the $\mathrm{BBURH}_{5,000}$ panel. Nevertheless, loci for NUP54 in BTA6 and HSA4 are consistent with its relative position on BBU7. Further mapping of region-specific markers should clarify these findings.
A first view at the telomere of BBU7 would suggest an inversion of eight loci in this area compared with BTA6. However, the region illustrates inconsistency in the locus order, which makes it crucial to assign more markers in this region. The BBU7 $\mathrm{RH}_{5,000}$ map is cytogenetically linked by MTTP and BM1329 to BBU7q21 and by CSN3 to BBU7q32 (Iannuzzi et al., 2003). No other cytogenetic anchors link the BBU7 $\mathrm{RH}_{5,000}$ map to the chromosome yet. Therefore, we suggest that some of the new markers on the RH map be mapped cytogenetically. This is a useful approach in comparative mapping studies for ordering complex $\mathrm{RH}$ linkage groups, as illustrated in the recent construction of an $\mathrm{RH}_{5,000}$ map for sheep chromosome 23 (Tetens et al., 2007).

As expected, the evolutionary conservation of chromosome segments between BBU7 and HSA4 follows principally the known comparative order of segments between BTA6 and HSA4 (Weikard et al., 2006, 2007). Small discrepancies in locus order within conserved segments might indicate small chromosome rearrangements, but could also be due to the insufficient resolution of the $\mathrm{BBU} 7 \mathrm{RH}_{5,000}$ map in specific regions of the chromosome. Segments in the middle part of BBU7 correspond with HSA4 p-arm and q-arm fragments covering the HSA4 centromere. This suggests that a centromere translocation in Bovidae or in Hominidae occurred during evolution. The suggestion of rearrangements between the two segments in the telomere region of BBU7 and HSA4 q-arm and p-arm are based on seven loci. The findings indicate noticeable rearrangements, which need further evaluation with more markers. The proximal syntenic block on BBU7, composed of nine loci, was located at the q-arm of HSA4, which indicates another chromosome rearrangement between BBU7 and HSA4. Based on the identified gene order, we suggest an inversion of loci between both chromosomes. However, on BBU7 this block includes genes of two distinct RH linkage groups. Consequently, a more precise characterization of this region on BBU7 is necessary.

In sum, the constructed $\mathrm{RH}_{5,000}$ map for BBU7 allows the description of variation and similarity between corresponding chromosomes of different species as cattle and human. The future assignment of numerous orthologous loci to the new identified breakpoints and to the start and end points of the BBU7 $\mathrm{RH}_{5,000}$ map will improve the presented map and contribute to the generation of a high-resolution gene map for the river buffalo genome.

\section{Acknowledgements}

We gratefully thank Elaine Owens, Christie Fickey, and Janice Elliott for providing the RH panel DNA and Janine Vogt for excellent technical assistance. 


\section{References}

- Agarwala R, Applegate DL, Maglott D, Schuler GD, Schäffer AA: A fast and scalable radiation hybrid map construction and integration strategy. Genome Res 10:350-364 (2000).

Altschul SF, Madden TL, Schäffer AA, Zhang J, Zhang Z, et al: Gapped BLAST and PSI-BLAST - A new generation of protein database search programs. Nucleic Acids Res 25:3389-3402 (1997).

-Amaral MEJ, Owens KE, Elliott JS, Fickey C, Schäffer AA, et al: Construction of a river buffalo (Bubalus bubalis) whole-genome radiation hybrid panel and preliminary $\mathrm{RH}$ mapping of chromosomes 3 and 10. Anim Genet 38:311-314 (2007).

Applegate D, Bixby R, Chvátal V, Cook W: The Traveling Salesman Problem: A Computational Study (Princeton University Press, Princeton, NJ, USA 2006).

Bishop MD, Kappes SM, Keele JW, Stone RT, Sunden SLF, et al: A genetic linkage map for cattle. Genetics 136:619-639 (1994).

De Hondt, Gallagher D, Oraby H, Othman OE, Bosma AA, et al: Gene mapping in the river buffalo (Bubalus bubalis L.): five syntenic groups. J Anim Breed Genet 114:79-85 (1997).

Di Meo GP, Perucatti A, Schibler L, Incarnato D, Ferrara L, et al: Thirteen type I loci from HSA4q, HSA6p, HSA7q and HSA12q were comparatively FISH-mapped in four river buffalo and sheep chromosomes. Cytogenet Cell Genet 90:102-105 (2000).

Di Meo GP, Perucatti A, Incarnato D, Ferretti L, Di Berardino D, et al: Comparative mapping of twenty-eight bovine loci in sheep (Ovis aries, $2 \mathrm{n}=54$ ) and river buffalo (Bubalus bubalis, $2 \mathrm{n}=50)$ by FISH. Cytogenet Genome Res 98: 262-264 (2002).

El Nahas SM, de Hondt HA, Womack JE: Current status of the river buffalo (Bubalus bubalis L.) gene map. J Hered 92:221-225 (2001).

FAO: Buffalo Production and Research. Borghese A (ed), Rome, Italy: 321 p (2005).

FAO: Livestock's Long Shadow: Environmental Issues and Options. Steinfeld H, Gerber P, Wassenaar T, Castel V, Rosales M, de Haan C (eds), Rome, Italy: 390 p (2006).

FAO: The State of the World's Animal Genetic Resources for Food and Agriculture. Rischkowsky B, Pilling D (eds) Rome, Italy: 523 p (2007).

Goldammer T, Kata SR, Brunner RM, Kuhn C, Weikard R, Womack JE, Schwerin M: High-resolution comparative mapping between human chromosomes 4 and 8 and bovine chromosome 27 provides genes and segments serving as positional candidates for udder health in cattle. Genomics 84:696-706 (2004).

Iannuzzi L: Standard karyotype of the river buffalo (Bubalus bubalis L., $2 \mathrm{n}=50$ ). Report of the committee for the standardization of banded karyotypes of the river buffalo. Cytogenet Cell Genet 67:102-113 (1994).
Iannuzzi L, Gallagher DS, Womack JE, Meo GP, Shelling CP, et al: FISH mapping of the alpha-S2 casein gene on river buffalo and cattle chromosomes identifies a nomenclature discrepancy in the bovine karyotype. Chromosome Res 4:159162 (1996).

Iannuzzi L, Di Meo GP, Perucatti A, Bardaro T: ZOO-FISH and R-banding reveal extensive conservation of human chromosome regions in euchromatic regions of river buffalo chromosomes. Cytogenet Cell Genet 82:210-214 (1998).

Iannuzzi L, Di Meo GP, Hayes H, Perucatti A, Incarnato D, et al: FISH-mapping of 31 type I loci (Texas markers) to river buffalo chromosomes. Chromosome Res 9:339-342 (2001).

Iannuzzi L, Di Meo GP, Perucatti A, Schibler L, Incarnato D, et al: The river buffalo (Bubalus bubalis, $2 \mathrm{n}=50$ ) cytogenetic map: assignment of 64 loci by fluorescence in situ hybridization and R-banding. Cytogenet Genome Res 102:65-75 (2003).

Ihara N, Takasuga A, Mizoshita K, Takeda H, Sugimoto $\mathrm{M}$, et al: A comprehensive genetic map of the cattle genome based on 3802 microsatellites. Genome Res 14:1987-1998 (2004).

Khatkar MS, Thomson PC, Tammen I, Raadsma HW: Quantitative trait loci mapping in dairy cattle: review and meta-analysis. Genet Sel Evol 36:163-190 (2004).

Khatkar MS, Thomson PC, Tammen I, Costa F, Raadsma HW: Combined QTL map of dairy cattle traits. http://www.vetsci.usyd.edu.au/reprogen/QTL_Map (2005).

Kumar S, Nagarajan M, Sandhu JS, Kumar N, Behl V, Nishanth G: Mitochondrial DNA analyses of Indian water buffalo support a distinct genetic origin of river and swamp buffalo. Anim Genet 38:227-232 (2007).

Miziara MN, Goldammer T, Stafuzza NB, Agarwala R, Schäffer AA, et al: Generation of a radiation hybrid map of river buffalo (Bubalus bubalis) chromosome one (BBU1). Cytogenet Genome Res 119:100-104 (2007).

NCBI Bos taurus (cow) build 3.1, www.ncbi.nlm nih.gov/mapview/map_search.cgi?taxid=9913.

NCBI Homo sapiens (human) build 36.2, www.ncbi nlm.nih.gov/mapview/map_search.cgi?taxid= 9606.

NCBI - National Center for Biotechnology Information, http://www.ncbi.nlm.nih.gov/.

Polineni P, Aragonda P, Xavier SR, Furuta R, Adelson DL: The bovine QTL viewer: a web accessible database of bovine Quantitative Trait Loci. BMC Bioinformatics 7:283 (2006).

Popescu CP, Long S, Riggs P, Womack J, Schmutz S, Fries R, Gallagher D, eds: Texas nomenclature, 1996 - Standardization of cattle karyotype nomenclature: report of the committee for the standardization of the cattle karyotype. Cytogenet Cell Genet 74:259-261 (1996).
Rexroad CE III, Owens EK, Johnson JS, Womack JE: A 12,000 rad whole genome radiation hybrid panel for high resolution mapping in cattle: characterization of the centromeric end of chromosome 1. Anim Genet 31:262-265 (2000).

Rozen S, Skaletsky H: Primer3 on the WWW for general users and for biologist programmers. Methods Mol Biol 132:365-386 (2000).

Schäffer AA, Rice ES, Cook W, Agarwala R: rh_tsp_ map 3.0: end-to-end radiation hybrid mapping with improved speed and quality control. Bioinformatics 23:1156-1158 (2007).

Schnabel RD, Kim J-J, Ashwell MS, Sonstegard TS, Van Tassell CP, et al: Fine-mapping milk production quantitative trait loci on BTA6: analysis of the bovine osteopontin gene. Proc Natl Acad Sci USA 102:6896-6901 (2005).

-Stafuzza NB, Ianella P, Miziara MN, Agarwala R, Schäffer AA: Preliminary radiation hybrid map for river buffalo chromosome 6 and comparison to bovine chromosome 3. Anim Genet 38: 406-409 (2007).

Stone RT, Pulido JC, Duyk GM, Kappes SM, Keele JW, Beattie CW: A small-insert bovine genomic library highly enriched for microsatellite repeat sequences. Mamm Genome 6:714-724 (1995).

Tetens J, Goldammer T, Maddox JF, Cockett NE, Leeb T, Drögemuller C: A radiation hybrid map of sheep chromosome 23 based on ovine BACend sequences. Anim Genet 38:132-140 (2007).

Weikard R, Goldammer T, Kühn C, Barendse W, Schwerin M: Targeted development of microsatellite markers from the defined region of bovine chromosome 6q21-31. Mamm Genome 8: 836-840 (1997).

Weikard R, Kühn C, Goldammer T, Laurent P, Womack JE, Schwerin M: Targeted construction of a high-resolution, integrated, comprehensive, and comparative map for a region specific to bovine chromosome 6 based on radiation hybrid mapping. Genomics 79:768-776 (2002).

-Weikard R, Kühn C, Goldammer T, Freyer G Schwerin M: The bovine PPARGC1A gene: molecular characterization and association of an SNP with variation of milk fat synthesis. Physiol Genomics 21:1-13 (2005).

-Weikard R, Goldammer T, Laurent P, Womack JE, Kuehn C: A gene-based high-resolution comparative radiation hybrid map as a framework for genome sequence assembly of a bovine chromosome 6 region associated with QTL for growth, body composition, and milk performance traits. BMC Genomics 7:53 (2006).

Weikard R, Goldammer T, Womack JE, Kuehn C: Forward to a detailed sequence map of bovine chromosome 6. Cytogenet Genome Res 116:7279 (2007). 